\title{
Packing Density Necessary to Reach a High Complete Occlusion Rate in Circumferential Unruptured Intracranial Aneurysms Treated with Stent-Assisted Coil Embolization
}

\author{
(D) R.T. Tosello, DU.C. Batista, DB.J.A. Pereira, and DR.L. Piske
}

\begin{abstract}
BACKGROUND AND PURPOSE: This study is a homogeneous series of circumferential unruptured intracranial aneurysms with large necks treated with stent-assisted coil embolization. Our purpose was to demonstrate which value of packing density is required to produce a durable occlusion.
\end{abstract}

MATERIALS AND METHODS: We retrospectively evaluated all patients with unruptured intracranial aneurysms who were treated with stent-assisted coil embolization having late angiographic control between 2004 and 2014, in a single large cerebrovascular referral center. To calculate the packing density, aneurysm volume, and coil volume, we used an on-line system.

RESULTS: In 49 circumferential unruptured intracranial aneurysms treated with stent-assisted coil embolization, 38.7\% ( $n=19)$ had complete occlusion in the immediate control. Of those with incomplete occlusion, $80 \%(n=24)$ progressed to complete occlusion in the late angiographic follow-up. At late angiographic control, $87.7 \%(n=43)$ of aneurysms were completely occluded. All aneurysms with a packing density of $\geq 19 \%$ were completely occluded. Packing density was the only statistically significant predictor of complete occlusion. None of the aneurysms with complete occlusion at immediate control or at late angiographic control had recurrence.

CONCLUSIONS: In circumferential aneurysms treated with stent-assisted coil embolization, packing density is the main predictor of complete occlusion. In this type of aneurysm, a packing density of $\geq 19 \%$ was enough to reach complete occlusion; knowing this is important to avoid higher packing densities that have more risk.

ABBREVIATIONS: $\mathrm{PD}=$ packing density; $\mathrm{SACE}=$ stent-assisted coil embolization; $\mathrm{UIA}=$ unruptured intracranial aneurysm

U

nruptured intracranial aneurysms (UIAs) are present in 3\% of the adult population and are increasingly detected due to more frequent use of noninvasive angiographic diagnostic imaging. ${ }^{1-3}$

Endovascular coiling for the treatment of intracranial aneurysms was first introduced into clinical use in 1990, and since then, the greatest concern has been the high recanalization rate, recently estimated to be approximately $20 \%{ }^{4,5}$ This occurs more often in large-neck aneurysms, ${ }^{6}$ which are currently treated with stent-assisted coil embolization (SACE).

In unassisted coil embolization, higher packing density (PD) rates are correlated with lower recanalization rates. ${ }^{7-10}$ It is likely that in SACE treatment, the packing density necessary to reach a

Received March 6, 2017; accepted after revision May 18.

From the Centro de Neuro-Angiografia, Hospital Beneficência Portuguesa de São Paulo-SP, Paulo-SP, Brazil.

Please address correspondence to Renato Tavares Tosello, MD, Rua Joao Moura, 975 Apt 131, Edifício Eliana; e-mail: retosello@hotmail.com

http://dx.doi.org/10.3174/ajnr.A5303 stable complete occlusion is lower, but there is no homogeneous study to confirm that possibility, to our knowledge.

The purpose of this study was to demonstrate which value of $\mathrm{PD}$ is likely to produce durable occlusion in a homogeneous series of circumferential, large-neck UIAs treated with SACE in a single cerebrovascular referral center.

\section{MATERIALS AND METHODS}

The study protocol was approved by a local institutional review board. This is a single-center retrospective review of our data bank from February 2004 to June 2014. Clinical and image records were independently reviewed by a member of the research team who did not participate in the treatment of any of the included patients. The patient demographics, treatment details and effects, results of follow-up, and complications were recorded.

All patients were treated under general anesthesia, and stentassisted coiling was performed on a biplane Integris Allura FD20/30 angiographic system (Philips Healthcare, Best, the Netherlands). Regular techniques were used, including prior use of dual antiplatelet therapy.

AJNR Am J Neuroradiol 38:1973-77 Oct 2017 www.ajnr.org 
Table 1: Relationship between the location and number of the aneurysms

\begin{tabular}{lcc}
\hline \multicolumn{1}{c}{ Location } & No. & $\%$ \\
\hline Middle cerebral artery & 11 & $22.4 \%$ \\
Anterior communicating artery & 9 & $18.4 \%$ \\
Basilar artery & 5 & $10.2 \%$ \\
Posterior communicating artery & 5 & $10.2 \%$ \\
Bifurcation of the internal carotid artery & 5 & $10.2 \%$ \\
Internal carotid artery & 3 & $6.1 \%$ \\
Pericallosal artery & 2 & $4.1 \%$ \\
Others & 9 & $18.4 \%$ \\
Total & 49 & $100 \%$ \\
\hline
\end{tabular}

From the 310 aneurysms in 271 patients treated with SACE, we selected 49 unruptured circumferential wide-neck aneurysms, not previously treated in 47 patients, with $3 \mathrm{D}$ reconstruction angiography before treatment and at least 1 late angiographic control. The mean time from the operation until the first follow-up was 7.0 months. Wide-neck aneurysms were defined as having at least 1 of the following criteria: neck size $\geq 4 \mathrm{~mm}$, dome-to-neck ratio $<1.5$, or a cylindric neck.

To calculate the packing density, volume of aneurysms, and volume of coils, we used an on-line system available at www. angiocalc.com. This calculation was based on the shape and size of the aneurysm and on the type and size of the coils. All aneurysms treated with coils that did not have calculations based on this site were excluded.

Of the 47 patients, 15 were men, and 32 , women. The mean age was 56.7 years. Of the 49 aneurysms, 32 had wide necks ( $>4 \mathrm{~mm}$ ), 42 had unfavorable dome-to-neck ratios ( $<1.5 \mathrm{~mm}), 26$ had wide necks and unfavorable dome-to-neck ratios, and 2 had cylindric necks.

The relationship between the location and number of aneurysms is shown in Table 1.

Aneurysm obliteration rates on the immediate control and first follow-up angiograms were classified as complete (100\%); any opacity in the neck or sac of the aneurysm was considered incomplete obliteration.

In the late angiographic control, we evaluated the rate of progression from incomplete to complete occlusion and whether there was recurrence of an aneurysm with initial complete occlusion. We compared these data with the location of the aneurysm, the volume of the aneurysm and coils, the $\mathrm{PD}$, and the type of stent used.

We used 4 types of stents: the Neuroform stent (Stryker Neurovascular, Kalamazoo, Michigan) in 35 procedures, the LEO stent (Balt Extrusion, Montmorency, France) in 16 procedures, the Enterprise stent (Codman \& Shurtleff, Raynham, Massachusetts) in 2 procedures, and the Solitaire stent (Solitaire AB neurovascular remodeling device; Covidien, Irvine, California) in 1 procedure.

\section{Statistical Analysis}

Statistical analysis was performed by using R statistical and computing software, Version 3.2.2 (http://www.r-project.org/). For the relationships between volume and packing and volume and incomplete occlusion, the Pearson correlation coefficient was calculated. To obtain the relationship among age, sex, aneurysm volume, packing density, and volume of coils and complete oc- clusion at 6-month follow-up, we used logistic regression. We also calculated the corresponding $95 \%$ confidence interval to verify the existence of the relationship. The relationships between a high percentage of PD and complete occlusion and between large aneurysms and incomplete occlusion were assessed with logistic regression analysis. $P$ values $<.05$ indicated a significant difference.

\section{RESULTS}

In the immediate control, complete occlusion occurred in $38.7 \%$ of aneurysms $(n=19)$, and incomplete occlusion, in $61.2 \%$ aneurysms $(n=30)$. However, of those who had incomplete occlusion, $80 \%(n=24)$ progressed to complete occlusion and the remaining 20\% $(n=6)$ had incomplete occlusion (Fig 1). At the late angiographic control, 43 aneurysms $(87.7 \%)$ had complete occlusion. There was no aneurysm recurrence in the first follow-up for those aneurysms that were completely occluded in the immediate control.

The mean volume of the 49 aneurysms was $175.2 \mathrm{~mm}^{3}$ (median, $329.7 \mathrm{~mm}^{3}$; range, $4.2-4849.9 \mathrm{~mm}^{3}$ ). The mean coil volume was $38.5 \mathrm{~mm}^{3}$ (median, $54.7 \mathrm{~mm}^{3}$; range, $1.5-396.3 \mathrm{~mm}^{3}$ ), and the average PD was $37.9 \%$ (median, $28.6 \%$; range, $2.8 \%-54.9 \%$ ).

Above $19 \%$ of $\mathrm{PD}$, all aneurysms were completely occluded, independent of their volume (Fig 2).

According to Fig 2, the aneurysms were subdivided into 2 groups on the basis of volume: $\mathrm{A},<179.6 \mathrm{~mm}^{3}$ ( $n=37$ ); B, $>179.6 \mathrm{~mm}^{3}$. In group A, all aneurysms except 1 had complete occlusion, independent of their PD. The only aneurysm incompletely occluded in this group was one in which we could not deploy a necessary second coil due to the impossibility of recatheterizing the aneurysm sac after the first coil. In group B, complete occlusion was reached for all aneurysms with a PD of $>19 \%$. Aneurysms of $>179.59 \mathrm{~mm}^{3}$ had a larger diameter, between 7.0 and $7.8 \mathrm{~mm}$.

The statistically significant correlation coefficient $(P<.05)$ between aneurysm volume and PD was -0.42 (95\% CI, -0.62 to $-0.15 ; P=.003)$, and the correlation between aneurysm volume and incomplete aneurysm occlusion was -0.44 (95\% CI, $0.18-$ $0.64 ; P=.002)$. The correlation coefficient between coil volume and PD was 0.26 (95\% CI, -0.50 to $0.02 ; P=.071)$, which is not statistically significant. Large volumes of coils are used in large aneurysms, which tend to have lower PD.

A multivariate analysis with predictive factors of complete aneurysm obliteration, including age, aneurysm volume, PD, and volume of coils, showed that the only statistically significant predictive factor was PD (Table 2).

Procedure-related complications occurred in 3 patients $(6.4 \%, 3 / 47)$. In 2 patients $(4.1 \%, 2 / 49)$, there was thrombosis of the stent after its release; one was treated with an intravenous infusion of a loading dose of abciximab (ReoPro), and the other, with an intra-arterial injection of tirofiban (Aggrastat) and mechanical thrombolysis, with full opening of the parent vessel. Both had a transient deficit and full recovery in 3 and 4 days, respectively. One patient $(2.1 \%, 1 / 47)$ had an asymptomatic vertebral artery dissection, and a stent was placed at the site of dissection. There was no neurologic deficit in any of the 3 patients at discharge. 

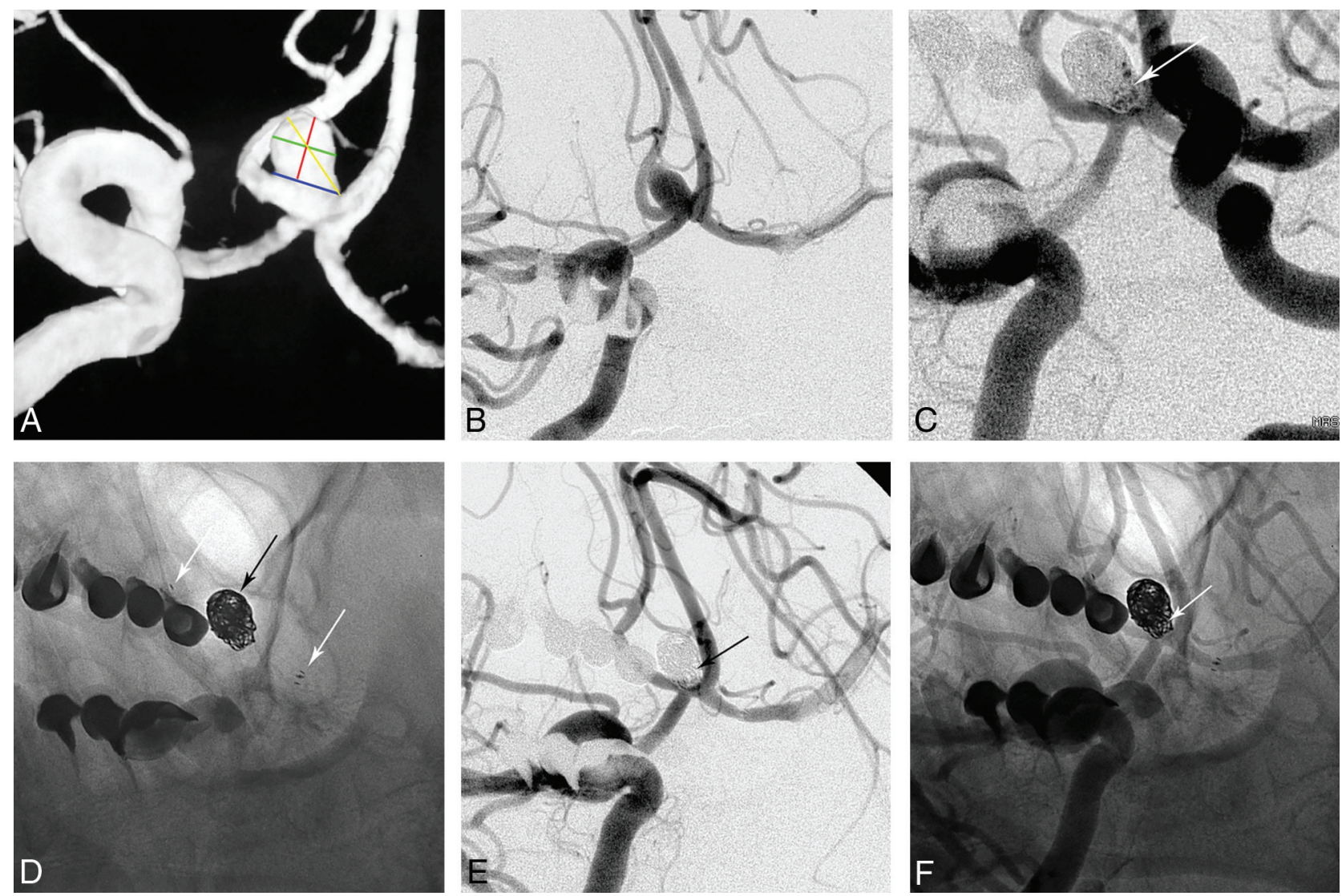

FIG 1. A 62-year-old man presenting with a small, incidental aneurysm of the anterior communicating artery. A 3D rotational angiogram $(A)$ was obtained before the embolization. Measurements were made of the neck (blue line), diameter parallel to the neck (green line), height (red line), and largest diameter (yellow line). Projection work after a right internal carotid contrast injection $(B)$ shows the relation of the anterior communicating artery aneurysm to the anterior cerebral arteries. Final control after simultaneous contrast injections in the internal carotid artery. $C$ and $D$, Residual neck flow (white arrow) after stent-assisted coil embolization (stent, white arrows; coils, black arrow). Six-month angiographic controls ( $E$ and $F$ ) show the evolution to complete occlusion (black and white arrows).

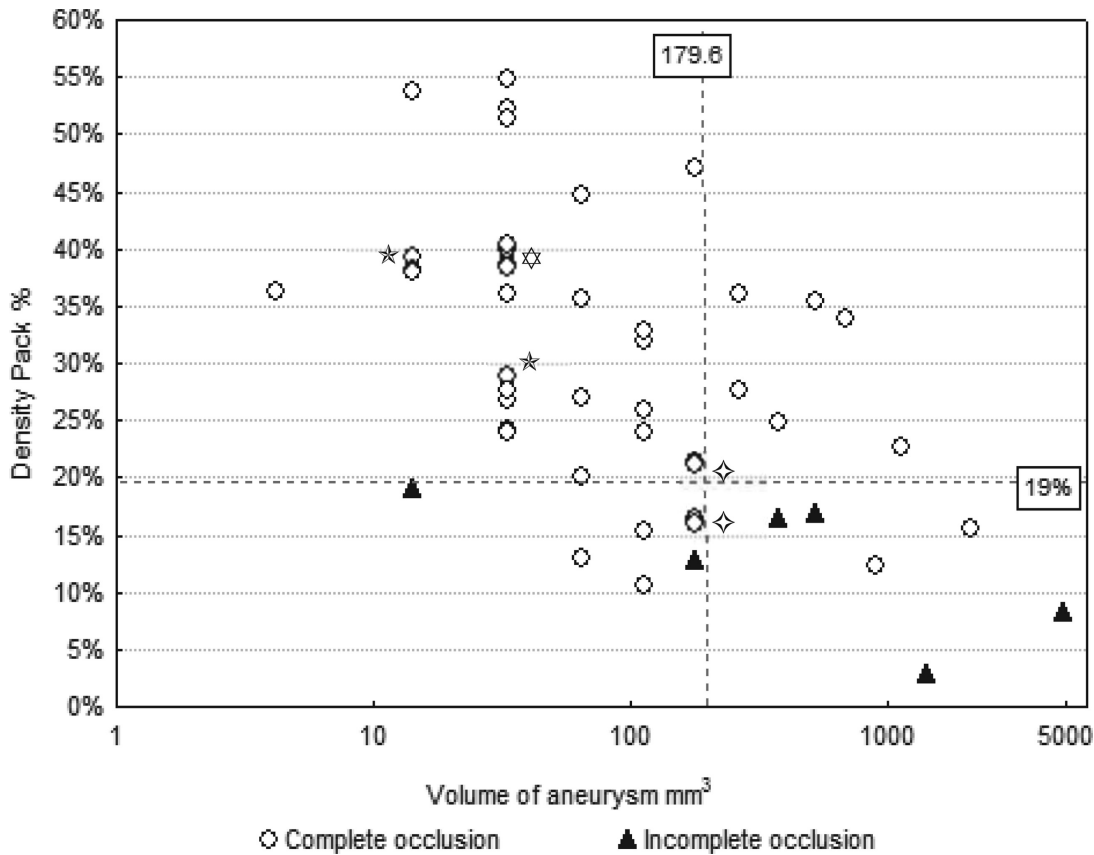

FIG 2. Results of the Pearson test, demonstrating that above $19 \%$ packing density, all aneurysms had complete occlusion. Regarding the volume, aneurysms above $179.6 \mathrm{~mm}^{3}$ had a higher rate of incomplete occlusion when the packing density was below $19 \%$. If $>1$ aneurysm is overlapping, note the following symbols: $\diamond, 2$ aneurysms, 朊, 3 aneurysms, 4 aneurysms.

\section{DISCUSSION}

Stent-assisted coil treatment for largeneck aneurysms has shown a higher rate of evolution to complete occlusion in the follow-up and a lower rate of late aneurysm recanalization compared with nonstented aneurysms. ${ }^{6,8,11-14}$ The mechanisms involved are hemodynamic modification of the inflow angle to the sac, the presence of more metal on the neck, and the scaffold provided by the stent and coils favoring better endothelialization. ${ }^{6,15-17}$ It is thought that the main predictor of immediate and late complete occlusion and the absence of aneurysm recurrence is the $\mathrm{PD}{ }^{8,11,12,18-22}$

However, we supposed that to achieve a higher $\mathrm{PD}$, it is necessary to place several coils inside the aneurysm, increasing the treatment time, the risk of thromboembolic and hemorrhagic complications, and the cost of the procedure.

Gallas et $\mathrm{al}^{23}$ found that $26 \%$ of aneurysms had an incomplete occlusion among 1036 aneurysms treated with coils. 
Table 2: Multivariate analysis of predictive factors for complete occlusion

\begin{tabular}{lccc}
\hline & Relative Risk & \multicolumn{1}{c}{$95 \% \mathrm{Cl}$} & $\boldsymbol{P}$ Value \\
\hline Sex & 0.933 & $0.254-6.045$ & .929 \\
Age & 0.746 & $0.089-2.345$ & .684 \\
Volume of the aneurysm & 1.001 & $1.000-1.002$ & .079 \\
Packing density $^{\mathrm{a}}$ & 0.876 & $0.657-0.955$ & .012 \\
Volume of the coils & 1.005 & $0.998-1.011$ & .123 \\
\hline
\end{tabular}

${ }^{\text {a }}$ Significance level is .05 .

Raymond and $\mathrm{Roy}^{7}$ reported that incomplete occlusion in the immediate control of aneurysms treated with coils is a risk factor for aneurysm recanalization. Piotin et $\mathrm{al}^{11}$ reported that aneurysms treated with SACE had lower recanalization rates than nonstented aneurysms. Lawson et $\mathrm{al}^{22}$ identified PD as a predictor of complete occlusion in aneurysms treated with SACE.

Chalouhi et $\mathrm{al}^{8,13}$ found an adequate PD of $12 \%-22 \%$ for complete occlusion of aneurysms in angiographic follow-up tests in 290 aneurysms treated with SACE, but the aneurysm recurrence rate was not reported.

Unlike others, our study considered only circumferential saccular UIAs, homogenizing the group to find the PD required for a high complete aneurysm occlusion rate, with low rates of recurrence and complications during the procedure.

Our study presented a rate of $38.7 \%(n=19)$ with complete occlusion and $61.2 \%(n=30)$ with incomplete occlusion in the immediate control. Of those in the latter group, $80 \%(n=24)$ progressed to complete occlusion in the late angiographic follow-up.

$\mathrm{PD}$ is the main predictor of complete occlusion and aneurysm recurrence. Our study found all aneurysms with PD $\geq 19 \%$ with initial incomplete occlusion evolved to complete occlusion in the late angiographic follow-ups, with a statistically significant relationship between the variable PD and the first follow-up, in agreement with the study of Chalouhi et al. ${ }^{8}$ Aneurysms with low PD $(<19 \%)$ tended to not evolve to complete occlusion. None of the aneurysms that were completely occluded had recurrence, emphasizing the relevance of the flow-remodeling theory in the use of stents. ${ }^{6,15-17}$

However, aneurysms with smaller $\left(<100 \mathrm{~mm}^{3}\right)$ and moderate $\left(100-1150.3 \mathrm{~mm}^{3}\right)$ volumes had high rates of complete occlusion (96\% and 85\%, respectively), compared with aneurysms with greater volume $\left(>1150.3 \mathrm{~mm}^{3}\right)$, demonstrating that smaller aneurysm volume can reach a better PD value with higher complete occlusion rates than those of large aneurysms, as described in the literature. 5,6,9,11,12,18,24 There was no statistically significant relation between the volume and packing density of an aneurysm: The $P$ value was .079 (statistical significance, $P<.05$ ), probably due to the low number of aneurysms.

Sluzewski et $\mathrm{al}^{9}$ reported that all aneurysms with packing densities of $>24 \%$ and a volume of $<600 \mathrm{~mm}^{3}$, treated with coil embolization, had complete occlusion. We found that all aneurysms with packing densities of $\geq 19 \%$ independent of their volume had complete occlusion. This finding shows that stents help neck endothelization, requiring fewer coils to reach complete occlusion. ${ }^{17}$

No patient with complete occlusion in our study needed retreatment, and our complication rate was $6 \%$. All patients were discharged without neurologic deficits and none died.
A limitation of our study is its retrospective, no randomization design in a single center with a small sample due to the inclusion of only circumferential UIAs. Another limitation is the use of a variety of regular stents and coils.

Today with the advancement of technology, new stents with lower porosity or double layers (eg, LVIS Blue, Lvis, Lvis Jr; MicroVention, Tustin, California) may produce different results, needing specific studies.

\section{CONCLUSIONS}

This study shows that the SACE technique has high rates of evolution from incomplete-to-complete occlusion of aneurysms, without recurrence. The PD is the main predictor for complete aneurysm occlusion. All aneurysms with PD of $\geq 19 \%$ achieved complete occlusion. For small aneurysms, the rate of complete occlusion was higher than in large aneurysms because it is difficult to achieve an optimal packing density in large aneurysms. The PD needed to occlude large-neck aneurysms treated with stents is lower than in those without stents.

\section{REFERENCES}

1. Wiebers DO, Whisnant JP, Huston J 3rd, et al; International Study of Unruptured Intracranial Aneurysms Investigators. Unruptured intracranial aneurysms: natural history, clinical outcome, and risks of surgical and endovascular treatment. Lancet 2003;362:103-10 CrossRef Medline

2. Etminan N, Brown RD Jr, Beseoglu K, et al. The unruptured intracranial aneurysm treatment score: a multidisciplinary consensus. Neurology 2015;85:881-89 CrossRef Medline

3. Seibert B, Tummala RP, Chow R, et al. Intracranial aneurysms: review of current treatment options and outcomes. Front Neurol 2011; 2:45 CrossRef Medline

4. Molyneux AJ, Kerr RS, Birks J, et al; ISAT Collaborators. Risk of recurrent subarachnoid haemorrhage, death, or dependence and standardised mortality ratios after clipping or coiling of an intracranial aneurysm in the International Subarachnoid Aneurysm Trial (ISAT): long-term follow-up. Lancet Neurol 2009;8:427-33 CrossRef Medline

5. Mascitelli JR, Oermann EK, De Leacy RA, et al. Predictors of treatment failure following coil embolization of intracranial aneurysms. J Clin Neurosci 2015;22:1275-81 CrossRef Medline

6. Colby GP, Paul AR, Radvany MG, et al. A single center comparison of coiling versus stent assisted coiling in $\mathbf{9 0}$ consecutive paraophthalmic region aneurysms. J Neurointerv Surg 2012;4: 116-20 CrossRef Medline

7. Raymond J, Roy D. Safety and efficacy of endovascular treatment of acutely ruptured aneurysms. Neurosurgery 1997;41:1235-45; discussion 1245-46 CrossRef Medline

8. Chalouhi N, Dumont AS, Hasan D, et al. Is packing density important in stent-assisted coiling? Neurosurgery 2012;71:381-86; discussion 386-87 CrossRef Medline

9. Sluzewski M, van Rooij WJ, Slob MJ, et al. Relation between aneurysm volume, packing, and compaction in 145 cerebral aneurysms treated with coils. Radiology 2004;231:653-58 CrossRef Medline

10. Chueh JY, Vedantham S, Wakhloo AK, et al. Aneurysm permeability following coil embolization: packing density and coil distribution. J Neurointerv Surg 2015;7:676-81 CrossRef Medline

11. Piotin M, Blanc R, Spelle L, et al. Stent-assisted coiling of intracranial aneurysms: clinical and angiographic results in 216 consecutive aneurysms. Stroke 2010;41:110-15 CrossRef Medline

12. Chalouhi N, Jabbour P, Singhal S, et al. Stent-assisted coiling of intracranial aneurysms: predictors of complications, recanalization, and outcome in 508 cases. Stroke 2013;44:1348-53 CrossRef Medline 13. Chalouhi N, Starke RM, Koltz MT, et al. Stent-assisted coiling 
versus balloon remodeling of wide-neck aneurysms: comparison of angiographic outcomes. AJNR Am J Neuroradiol 2013;34: 1987-92 CrossRef Medline

14. Hong Y, Wang YJ, Deng Z, et al. Stent-assisted coiling versus coiling in treatment of intracranial aneurysm: a systematic review and meta-analysis. PLoS One 2014;9:e82311 CrossRef Medline

15. Tanemura H, Ishida F, Miura $\mathrm{Y}$, et al. Changes in hemodynamics after placing intracranial stents. Neurol Med Chir (Tokyo) 2013;53: 171-78 CrossRef Medline

16. Tateshima S, Tanishita K, Hakata Y, et al. Alteration of intraaneurysmal hemodynamics by placement of a self-expandable stent: laboratory investigation. J Neurosurg 2009;111:22-27 CrossRef Medline

17. Lopes D, Sani S. Histological postmortem study of an internal carotid artery aneurysm treated with the Neuroform stent. Neurosurgery 2005;56:E416; discussion E CrossRef Medline

18. Geyik S, Yavuz K, Yurttutan N, et al. Stent-assisted coiling in endovascular treatment of $\mathbf{5 0 0}$ consecutive cerebral aneurysms with long-term follow-up. AJNR Am J Neuroradiol 2013;34:2157-62 CrossRef Medline

19. Sadato A, Adachi K, Hayakawa M, et al. Effects of anatomic characteristics of aneurysms on packing density in endovascular coil embolization: analysis of a single center's experience. Neurosurg Rev 2016;39:109-14; discussion 114 CrossRef Medline

20. Ozretić D, Radoš M, Pavliša G, et al. Long-term angiographic outcome of stent-assisted coiling compared to non-assisted coiling of intracranial saccular aneurysms. Croat Med J 2015;56:24-31 CrossRef Medline

21. Bouillot $P$, Brina $O$, Ouared $R$, et al. Particle imaging velocimetry evaluation of intracranial stents in sidewall aneurysm: hemodynamic transition related to the stent design. PLoS One 2014;9: e113762 CrossRef Medline

22. Lawson MF, Newman WC, Chi YY, et al. Stent-associated flow remodeling causes further occlusion of incompletely coiled aneurysms. Neurosurgery 2011;69:598-603; discussion 603-04 CrossRef Medline

23. Gallas S, Januel AC, Pasco A, et al. Long-term follow-up of $\mathbf{1 0 3 6}$ cerebral aneurysms treated by bare coils: a multicentric cohort treated between 1998 and 2003. AJNR Am J Neuroradiol 2009;30: 1986-92 CrossRef Medline

24. Yang H, Sun Y, Jiang Y, et al. Comparison of stent-assisted coiling vs coiling alone in $\mathbf{5 6 3}$ intracranial aneurysms: safety and efficacy at a high-volume. Neurosurgery 2015;77:241-47; discussion 247 CrossRef Medline 